\title{
Correction: Risk Factors Associated With Epidural Use
}

\author{
Samuel M. Lancaster ${ }^{\mathrm{a}, \mathrm{c}}$, Ursula M. Schick ${ }^{\mathrm{b}}$, Morwan M. Osmanª, \\ Daniel A. Enquobahrie ${ }^{a}$
}

Corrections to article "Risk Factors Associated With Epidural Use", by Lancaster et al, published in Vol. 4, No. 2, 2012, p119-126, doi: $\mathrm{http}: / / \mathrm{dx}$.doi.org/10.4021/jocmr810w.

The authors would like to make the following corrections in "Background" section of the Abstract::

Change from:

Background: Identify variables associated with intrapartum epidural use.

To:

Background: Epidural use is associated with a more comfortable labor and a better overall labor experience. While it is becoming widespread, epidural use nonetheless varies across patient subgroups. A better understanding of factors associated with epidural use may help elucidate disparities in its utilization and underscore the importance of epidurals in certain circumstances.

\footnotetext{
Manuscript accepted for publication May 24, 2016

aDepartment of Epidemiology, University of Washington, Seattle, Washington, USA

bDepartment of Public Health Genetics, University of Washington, Seattle, Washington, USA

'Corresponding author: Samuel M. Lancaster, Department of Genome Sciences, Box 355065, 3720 15th Ave. NE, Seattle, WA, USA.

Email: slancast@stanford.edu
}

doi: http://dx.doi.org/10.14740/jocmr810wc1

Articles (C) The authors | Journal compilation (C) J Clin Med Res and Elmer Press Inc ${ }^{\mathrm{TM}}$ | www.jocmr.org 